\title{
Fluorescein-Labeled Starch Maleate Nanoparticles as Sensitive Fluorescent Sensing Probes for Metal Ions
}

\author{
Suk Fun Chin, ${ }^{1}$ Aressa Azman, ${ }^{1}$ Suh Cem Pang, ${ }^{1}$ and Sing Muk $\mathbf{N g}^{2}$ \\ ${ }^{1}$ Department of Chemistry, Faculty of Resource Science and Technology, Universiti Malaysia Sarawak, \\ 94300 Kota Samarahan, Sarawak, Malaysia \\ ${ }^{2}$ Faculty of Engineering, Computing and Science, Swinburne University of Technology, 93350 Kuching, Sarawak, Malaysia \\ Correspondence should be addressed to Suk Fun Chin; sukfunchin@gmail.com
}

Received 4 July 2013; Revised 7 December 2013; Accepted 7 December 2013; Published 28 January 2014

Academic Editor: Alan K. T. Lau

Copyright (C) 2014 Suk Fun Chin et al. This is an open access article distributed under the Creative Commons Attribution License, which permits unrestricted use, distribution, and reproduction in any medium, provided the original work is properly cited.

\begin{abstract}
Fluorescein 5(6)-isothiocyanate starch maleate (FISM) nanoparticles were prepared by covalently attached fluorescein 5(6)isothiocyanate (FITC) with starch maleate. FISM nanoparticles with a mean particle size of $87 \mathrm{~nm}$ were formed via self-assembly upon precipitation in ethanolic solution. FISM nanoparticles were strongly fluorescent with maximum emission wavelength of $518 \mathrm{~nm}$. The fluorescence of FISM nanoparticles can be quenched by silver $\left(\mathrm{Ag}^{+}\right)$and lead $\left(\mathrm{Pb}^{2+}\right)$ ions in a concentration dependent manner. We have demonstrated the first use of FISM nanoparticles as cheap and effective fluorescent sensing probes for $\mathrm{Ag}^{+}$and $\mathrm{Pb}^{2+}$ ions with detection limits as low as $2.55 \times 10^{-5} \mathrm{M}$ and $3.64 \times 10^{-5} \mathrm{M}$, respectively.
\end{abstract}

\section{Introduction}

Polysaccharides such as starch, chitosan, alginate, and dextran have received great interest as precursor materials for the preparation of nanoparticles as they are abundantly available, of low cost, renewable, and nontoxic in nature [1,2]. Besides, these biopolymers are suitable to be used for various biomedical applications due to their unique properties that are biocompatible and biodegradable [3]. Recently, the use of polysaccharides as precursor materials for preparation of fluorescent nanoparticles has considerably increased [48]. Various polysaccharides-based fluorescent nanoparticles have been reported such as fluorescein-labeled starch acetates [9], fluorescein-labeled dextran propionate [10, 11], fluorescein-labeled dextrin nanoparticles [6], magnetic fluorescent alginate nanoparticles [12], and fluorescent chitosan nanoparticles [13-15] in pieces of literature. These fluorescent polysaccharides-based nanoparticles have been utilized in various applications such as bioimaging [16], biosensing, chemical sensing [17], pH sensing [18], and drug delivery [19].

Physical entrapment of fluorophores is one of the commonly used approaches to incorporate fluorescent molecules into nanoparticles due to its simplicity [7]. However, this type of physical entrapment approach suffers from several major setbacks such as possible leaching of fluorophores that subsequently leads to toxicity of the cell, contamination of biological samples, and incorrect signal measurements [20]. In order to overcome these problems, some researchers have attempted to covalently attach fluorophores onto polysaccharides molecules $[9,11]$. Covalent attachment is proven to reduce the leaching of fluorophores, provide good photostability, enhance lifetime, and produce stable fluorescent signals [20].

Fluorescence quenching has been employed extensively for the detection and quantification of various metal ions due to its high sensitivity, ease of handling, low cost, portability, and the fact that it can deliver rapid results [21, 22]. Fluorescence quenching involves the use of highly fluorescent fluorophore where intensity would be greatly reduced or quenched completely in the presence of a target analyte. Many metal ions are known to be fluorescence quenchers that could be detected using this method [23].

In this work, we have successfully synthesized fluorescein 5(6)-isothiocyanate-labeled starch maleate (FISM) nanoparticles by covalently attaching fluorescein 5(6)-isothiocyanate (FITC) with starch maleate. The potential application of FISM 
nanoparticles as sensitive fluorescent probes for heavy metal ions detection was demonstrated. Our results showed that FISM nanoparticles could act as sensing probes for selective detection of $\mathrm{Ag}^{+}$and $\mathrm{Pb}^{2+}$ ions in aqueous systems.

\section{Materials and Methods}

2.1. Materials. Native sago starch (Metroxylon sagu) powder was purchased from local market at Kuching (Sarawak, Malaysia). Fluorescein 5(6)-isothiocyanate (FITC) was obtained from Sigma (USA); dibutyltin dilaurate (DBTDL), maleic anhydride, 2-(dimethyl-amino) pyridine (DMAP), dimethyl sulfoxide (DMSO), sodium hydroxide, and sodium dihydrogen phosphate monohydrate were purchased from Merck (Hohenbrunn, Germany). N,N-Dimethylformamide (DMF) was purchased from J.T. Baker (Phillipsburg, USA) and absolute ethanol, disodium hydrogen phosphate, and acetic acid were purchased from HmbG Chemicals (Hamburg, Germany). Sodium acetate hydrated and sodium hydrogen carbonate were obtained from Bendosen Laboratory Chemicals (Bendosen, Norway). $\mathrm{AgNO}_{3}, \mathrm{Ca}\left(\mathrm{NO}_{3}\right)_{2}$, $\mathrm{CO}\left(\mathrm{NO}_{3}\right)_{2}, \quad \mathrm{Cr}\left(\mathrm{NO}_{3}\right)_{2}, \quad \mathrm{Cu}\left(\mathrm{NO}_{3}\right)_{2}, \quad \mathrm{HgCl}_{2}, \quad \mathrm{Mg}\left(\mathrm{NO}_{3}\right)_{2}$, $\mathrm{Ni}\left(\mathrm{NO}_{3}\right)_{2}, \mathrm{~Pb}\left(\mathrm{NO}_{3}\right)_{2}, \mathrm{Zn}\left(\mathrm{NO}_{3}\right)_{2}$, and $\mathrm{Al}\left(\mathrm{NO}_{3}\right)_{3}$ were purchased from R\&M Marketing (Essex, UK). Ultrapure water $(18.2 \mathrm{M} \Omega \cdot \mathrm{cm})$ obtained from a Water Purifying System (Model: ELGA, Ultra Genetic) was used throughout the experiments. Native sago starch powder and all chemicals were used without further purification.

\subsection{Preparation of Fluorescein-Labeled Starch Maleate (FISM)} Nanoparticles. Starch maleate was synthesized based on method adapted from Tay et al. [24, 25] and Li et al. [9] with slight modification. About $2.0 \mathrm{~g}$ of native sago starch powder $\left(12.34 \times 10^{-3}\right.$ mole anhydroglucose unit) was dissolved in $50 \mathrm{~mL}$ of $\mathrm{N}, \mathrm{N}$-dimethylformamide (DMF). The solution was stirred for about $15-20 \mathrm{~min}$ at $90^{\circ} \mathrm{C}$. Then $3.63 \mathrm{~g}$ of maleic anhydride $\left(37.04 \times 10^{-3}\right.$ mole $)$ and $30 \mu \mathrm{L}$ DMAP were added into the mixture. The mixture was stirred continuously ( $900 \mathrm{rpm})$ at $90-95^{\circ} \mathrm{C}$ for $4 \mathrm{~h}$. Subsequently, the mixture was cooled to room temperature and precipitated with ultra-pure water. The precipitate was rinsed several times with ultra-pure water to remove any unreacted salts.

For synthesis of FISM, $1.5 \mathrm{~g}$ of starch maleate reacted with various concentrations of FITC $(0.05,0.25,0.5,1.0,2.0$, and $3.0 \mathrm{mg} / \mathrm{mL}$ ) in $10 \mathrm{~mL}$ DMSO for $6 \mathrm{~h}$ at $90-95^{\circ} \mathrm{C}$. Also, $1.6 \mathrm{~mL}$ of DBTDL was added to the solution as a catalyst. The resulting FISM solution was added dropwise into ethanol to produce FISM nanoparticles via precipitation. The FISM nanoparticles were purified by dialyzing the samples using dialysis membranes against ultra-pure water for $24 \mathrm{~h}$ before being used for further study.

\subsection{Characterization of FISM Nanoparticles}

2.3.1. Spectroscopy Characterizations. The absorbance of FISM nanoparticles was recorded using a UV/Vis spectrophotometer (Model: JASCO V-630). Infrared spectra of the samples were characterized using a Fourier transformed infrared (FTIR) spectroscopy (Model: PerkinElmer). Sample was mixed into $\mathrm{KBr}$ /sample pellets and the FITR spectra were recorded within the wavenumber range of $4000-400 \mathrm{~cm}^{-1}$. The fluorescence intensity was measured at room temperature using spectrofluorometer (Model: Cary Eclipse, Varian) at a fixed excitation wavelength of $495 \mathrm{~nm}$. $100 \mu \mathrm{L}$ of stock solution of FISM $(2 \mathrm{mg} / \mathrm{mL})$ in ultra-pure water was mixed with $2 \mathrm{~mL}$ of buffer solution in a cuvette. The fluorescence intensity of sample in buffer solution at different $\mathrm{pH}$ (4.012.0) was recorded at fixed emission wavelength of $518 \mathrm{~nm}$. The excitation and emission slits were both set at $5.0 \mathrm{~nm}$. The particle sizes and morphology of FISM nanoparticles were observed by using a transmission electron microscope (TEM) (Model: JEOL JEM-1230). The diameters of around 100 nanoparticles were measured randomly using the SmileView software. Fluorescence image of FISM nanoparticles was obtained with inverted microscope system (Olympus, Model: IX51) with a 100W high pressure mercury lamp (Olympus, Model: BH2-RFL-T3) and digital color camera DCC (Olympus, Model: XC30).

2.3.2. Determination of Degree of Substitution (DS). DS of starch maleate was determined based on the method reported by Stojanovic et al. [26] with slight modifications. About $0.5 \mathrm{~g}$ of the starch maleate sample was added to $20 \mathrm{~mL}$ of $0.2 \mathrm{M} \mathrm{NaOH}$ solution. The mixture was stirred until the entire precursor was dissolved completely. The solution was transferred to a $100 \mathrm{~mL}$ volumetric flask, which was then filled up to the mark with ultra-pure water. $25 \mathrm{~mL}$ of the solution was transferred to Erlenmeyer flask, excess of $\mathrm{NaOH}$ solution in the sample was back titrated with $0.05 \mathrm{M}$ of $\mathrm{HCl}$ using phenolphthalein as an indicator. Native starch sample was also titrated as the blank sample. The difference between the starch maleate sample and blank sample which were titrated in excess of $\mathrm{NaOH}$ was a measure of maleate content in the sample. The titration was repeated three times and the average volume of $\mathrm{HCl}$ was used for the calculations. The amount of carboxylic terminal $(\mathrm{COOH})$ was determined using (1) and DS was calculated according to (2):

$$
\begin{gathered}
n \mathrm{COOH}=\left(V_{b}-V\right) \cdot C_{\mathrm{HCl}} \cdot 4, \\
\mathrm{DS}=\frac{162 \times n \mathrm{COOH}}{\mathrm{Mds}-99 n \mathrm{COOH}},
\end{gathered}
$$

where $n \mathrm{COOH}$ is the amount of $\mathrm{COOH}$ (in mole) present in the sample; $V_{b}$ is the volume of $0.05 \mathrm{M} \mathrm{HCl}$ (in $\mathrm{mL}$ ) used for titration of blank; $V$ is volume of $\mathrm{HCl}$ (in $\mathrm{mL}$ ) used for the titration of starch maleate; $C_{\mathrm{HCl}}$ is the molarity of $\mathrm{HCl}$ solution and 4 is the ratio of the total volume of solution $(100 \mathrm{~mL}) ; 162 \mathrm{~g} / \mathrm{mole}$ is the molecular weight of anhydroglucose unit (AGU); Mds is the mass of dry sample (in $\mathrm{g}$ ) and $99 \mathrm{~g} / \mathrm{mole}$ is the net increase in the molecular weight of the maleate group substituted.

2.3.3. Labeling Efficiency (LE). The concentration of FITC grafted onto starch maleate was determined by correlating the fluorescence intensity of the sample to a calibration curve constructed from known concentration of free FITC 


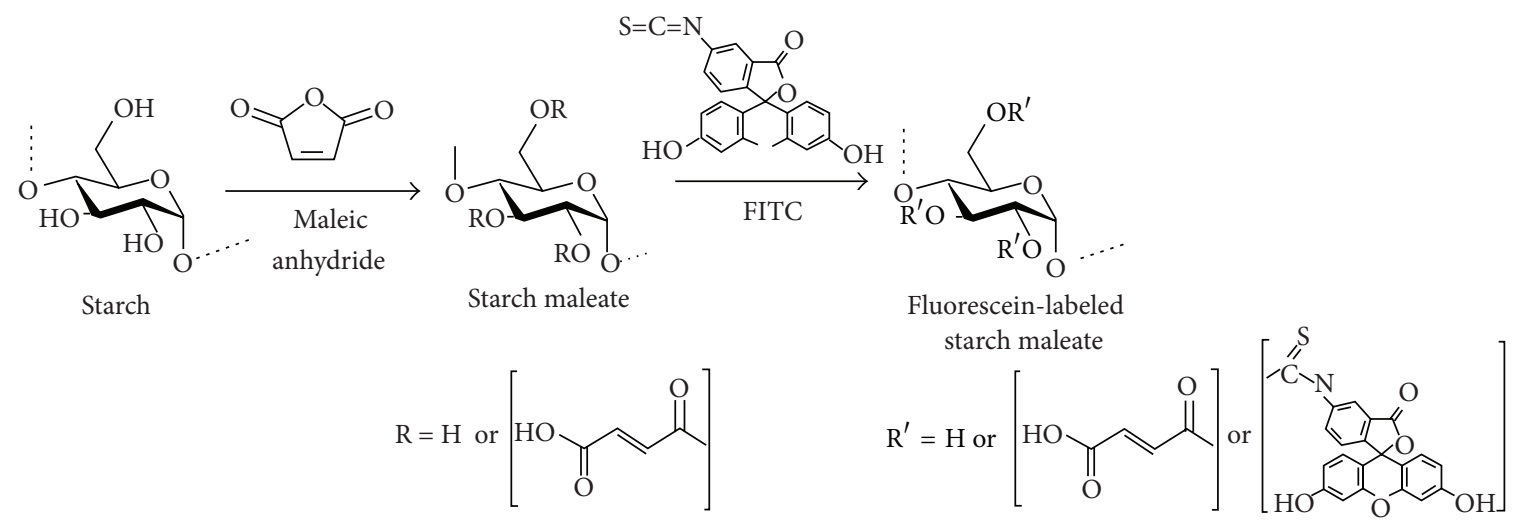

FIGURE 1: Schematic diagram of the reaction between starch, starch maleate, and fluorescein 5(6)-isothiocyanate starch maleate.

in DMSO. The degree of substitution (in percentage) of FITC in FISM sample was calculated according to

$$
\% \mathrm{FITC}=\frac{[\mathrm{FITC}]}{[\mathrm{FISM}]} \times 100,
$$

where [FITC] is concentration of FITC in FISM sample (in $\mathrm{mg} / \mathrm{mL}$ ) and [FISM] is the concentration of FISM sample (in $\mathrm{mg} / \mathrm{mL}$ ).

\section{Results and Discussion}

3.1. Synthesis of FISM Nanoparticles. FISM nanoparticles were synthesized from native sago starch grafted with maleic and fluorophore groups. Starch was esterified using maleic anhydride and then labeled with FITC. DMF and DMSO were used as solvents instead of water during the synthesis of starch maleate (SM) and fluorescein-labeled starch maleate (FISM), as this esterification reaction would release water as a side product. As esterification reaction is a reversible reaction, this reaction can proceed in either the forward (left to right) or the reverse direction depending on conditions. Increasing the water content tends to drive the reaction in the reverse reaction, which is undesirable as the aim is to produce more of SM and FISM. Thus, DMF and DMSO were used as solvents to maintain the mixture with lower yield of water so that the equilibrium would give forward reaction to produce greater yield of product [27]. DMAP acted as a nucleophilic catalyst [28] for the esterification reaction with anhydrides, where it catalyzed the reaction of maleic anhydride and hydroxyl $(\mathrm{OH})$ group of starch. DMAP attacked the anhydrides to form intermediate amide which was more reactive towards nucleophilic attack than the original anhydride. Starch molecules have $\mathrm{OH}$ groups that are able to act as nucleophiles, attacking the intermediate amide or the activated carbonyl carbon of maleic anhydride to produce starch maleate. For synthesis of FISM, DBTDL was used to catalyze the reaction between FITC molecules with starch maleate molecules by activating isothiocyanate molecules of FITC. The OH group of starch maleate attacked this activated isothiocyanate carbon atom which then further reacted by propagating the polymer to give thiocarbamate ester and regenerating the catalytic species [29].
The esterification processes through DMF/DMAP and DMSO/DBTDL systems represent an effective method for synthesizing fluorescent starch maleate. The labeling reaction was based on the covalent binding between the isothiocyanate group of FITC and the $\mathrm{OH}$ group of starch as illustrated by the scheme in Figure 1. The degree of substitution (DS) of starch maleate was determined to be 1.64, whereas DS of FITC onto starch maleate was $0.63 \%$. The DS of starch maleate obtained from this study was higher as compared to the previously reported of $0.03-0.21$ [25]. This could be due to the fact that the DMAP used in this study was a more effective catalyst as compared to $\mathrm{NaOH}$ used in the previous study.

3.2. Spectroscopy Characterizations. FTIR spectra of starch maleate (SM) and fluorescein 5(6)-isothiocyanate-labeled starch maleate (FISM) were shown in Figure 2. New absorption bands belonged to carbonyl group of maleate were observed in the spectra of starch maleate at 1728 and $1718 \mathrm{~cm}^{-1}$. This observation suggested that the starch maleate was successfully formed during the esterification process. Besides, the absence of absorption peak that corresponded to ring anhydride carbonyl group at 1783 and $1857 \mathrm{~cm}^{-1}$ in starch maleate showed that the sample was not contaminated with maleic anhydride. The absorption peak at $1638 \mathrm{~cm}^{-1}$ was due to tightly bound water present in the samples, and this peak was also overlapped with the $\mathrm{C}=\mathrm{C}$ stretching of maleate on the starch chain.

After the reaction of starch maleate with FITC, the intensity of absorption peaks at around $1638 \mathrm{~cm}^{-1}$ and $1653 \mathrm{~cm}^{-1}$ was observed to increase due to increase in $\mathrm{C}=\mathrm{C}$ stretching present in FITC molecules and the formation of thiocarbamate bond of the fluorescein derivatives. This supported the suggestion that a reaction had taken place between isothiocyanate group in the fluorescein and the $\mathrm{OH}$ group of starch maleate.

The UV/Vis absorption spectra of FISM nanoparticles and free FITC in ultra-pure water ( $\mathrm{pH}$ 6.8) and buffer solution of $\mathrm{pH} 9$ were presented in Figure 3. FISM nanoparticles showed two broad absorption peaks at around 450 and 


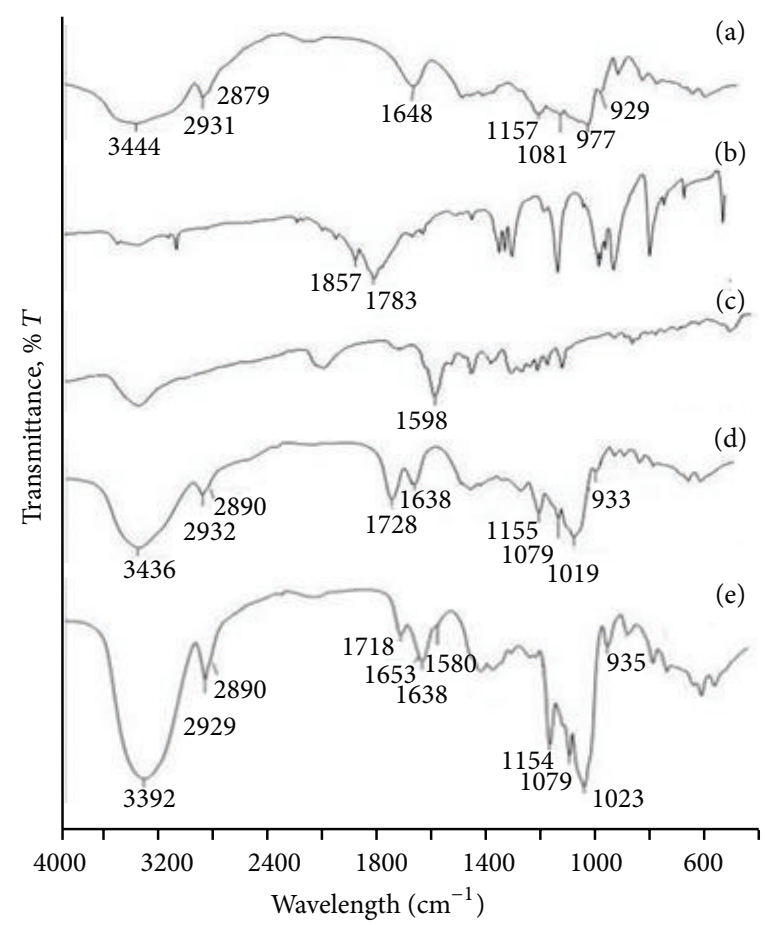

Figure 2: FTIR spectra of (a) native sago starch, (b) maleic anhydride, (c) FITC, (d) starch maleate, and (e) fluorescein 5(6)-isothiocyanatelabeled starch maleate (FISM) nanoparticles.

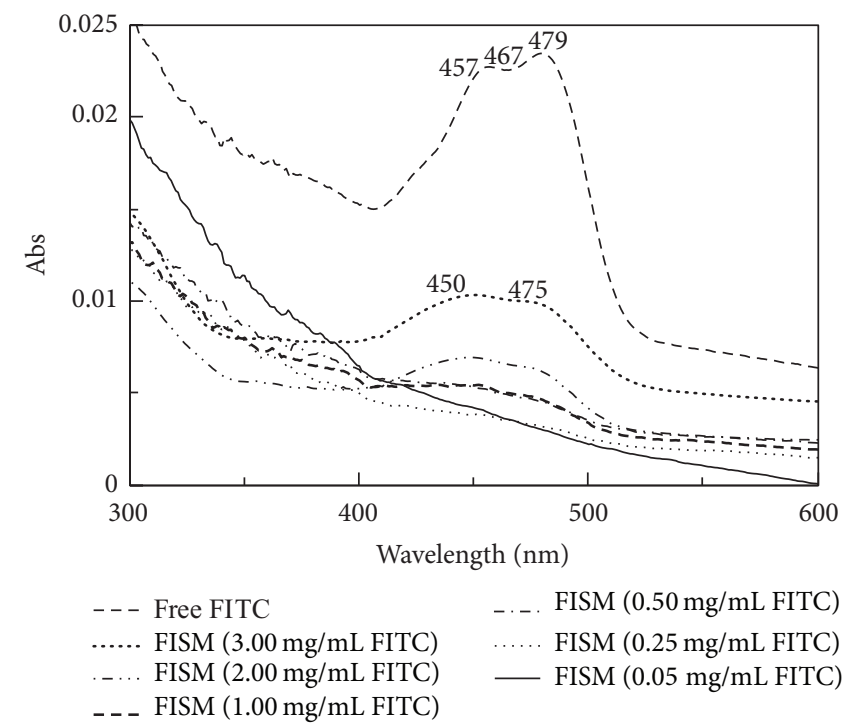

(a)

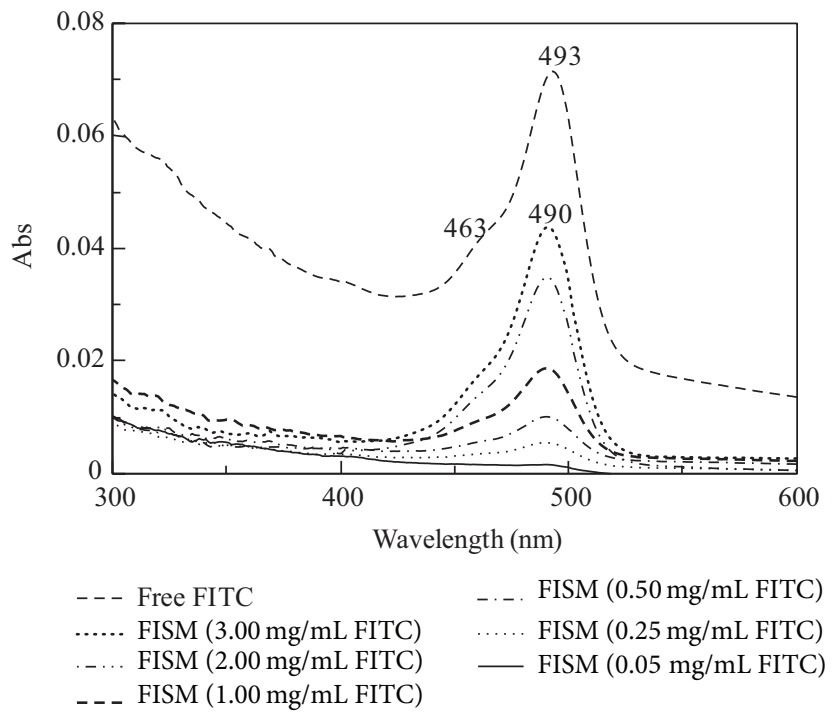

(b)

FIGURE 3: UV/Vis absorption of an aqueous suspension of free FITC and FISM nanoparticles with different concentrations of FITC in (a) ultra-pure water and (b) buffer solution of $\mathrm{pH} 9$.

$475 \mathrm{~nm}$ in water ( $\mathrm{pH} \sim 6.8$ ) which were close to the reported typical absorption peaks at 457, 467 and $479 \mathrm{~nm}$ for free FITC [30]. Both free FITC and FISM nanoparticles showed absorption maxima at around $490 \mathrm{~nm}$ in basic solution. These absorption peaks were not observed in the unlabeled starch maleate. The presence of the typical absorption peaks of FITC confirmed the presence of FITC in FISM.
The intensity of UV/Vis absorption of FISM was strongly dependent on the $\mathrm{pH}$ of the solution. The intensity of absorption was higher in basic solution as compared to acidic solution. This is because FITC is present in dianionic form and more soluble in basic condition $[9,28,31]$. However, FITC is mainly in monoanionic form [32] and has lower solubility in acidic solution. 


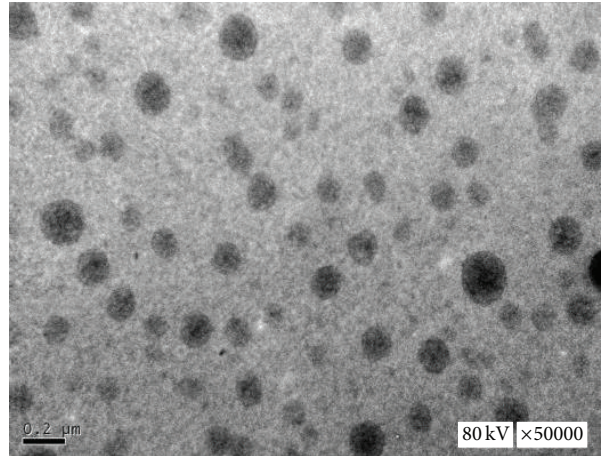

(a)

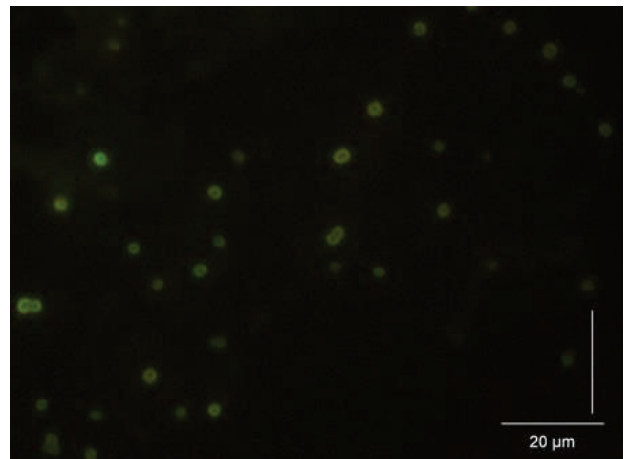

(b)

FIGURE 4: (a) TEM micrograph and (b) fluorescence image of FISM nanoparticles.

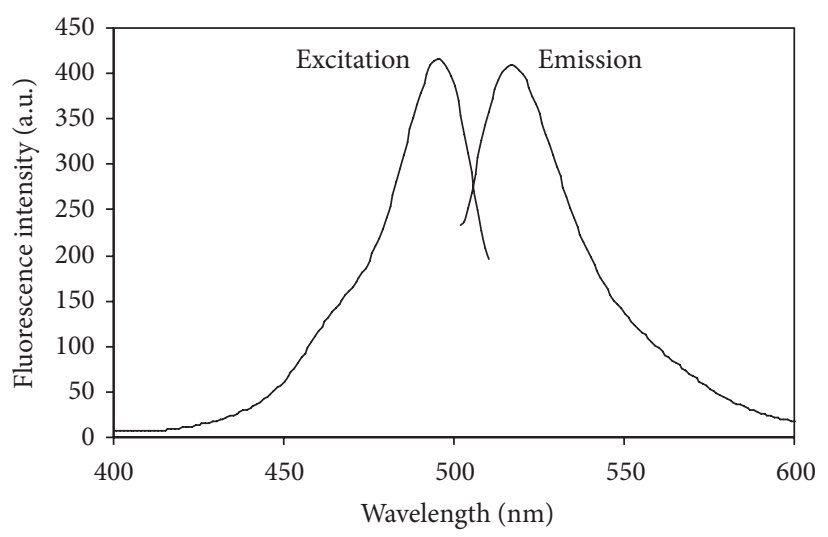

(a)

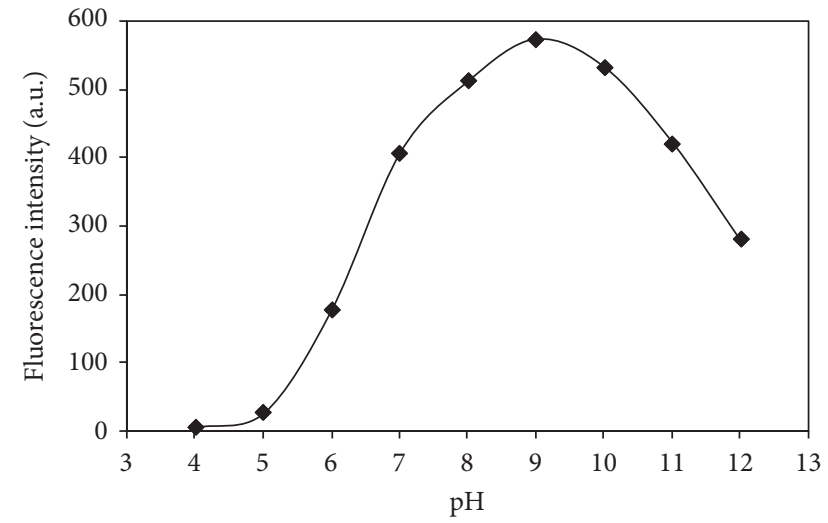

(b)

FIGURE 5: (a) Excitation and emission spectra of FISM in buffered solution of pH 7 and (b) fluorescence intensity of FISM nanoparticles in various $\mathrm{pH}$ buffer solutions in the range 4 to 12 . $\left(\lambda_{\mathrm{ex}}=495 \mathrm{~nm}\right.$ and $\left.\lambda_{\mathrm{em}}=518 \mathrm{~nm}\right)$.

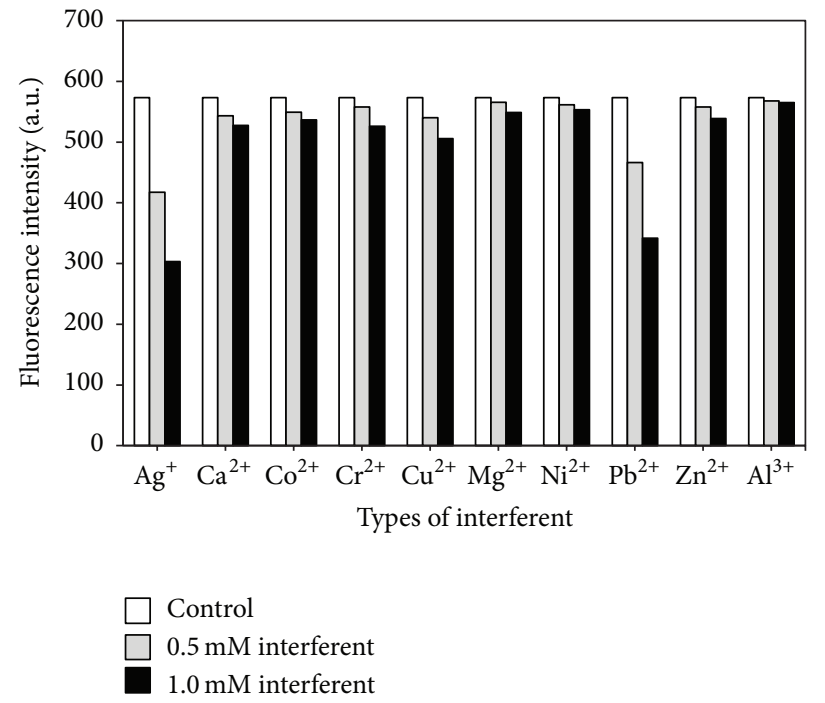

FIGURE 6: Effect of types of interferent on fluorescence intensity of FISM nanoparticles in pH 9 buffer solution. 


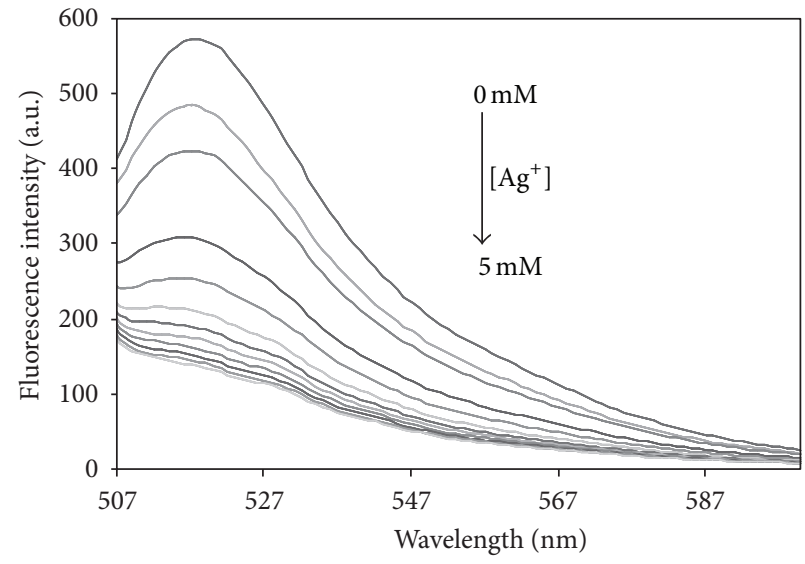

(a)

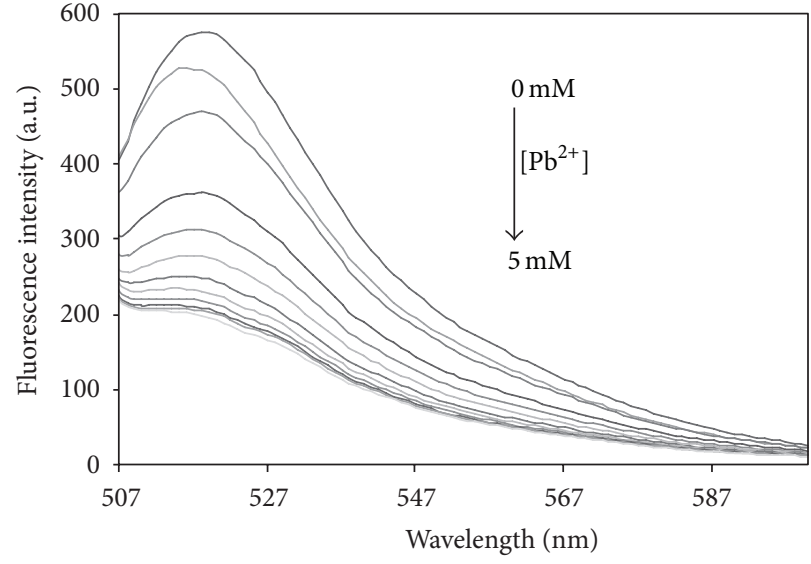

(b)

FIgURE 7: The fluorescence quenching curves of FISM by (a) $\mathrm{Ag}^{+}$and (b) $\mathrm{Pb}^{2+}$, respectively.

3.3. Morphology of FISM Nanoparticles. FISM nanoparticles were observed to be discrete and spherical in shape as shown by the TEM in Figure 4. The maleated process imparted hydrophobicity and consequently prevented rapid aggregation and gelation of the starch-based nanoparticles in aqueous solution [24]. The mean particle size of the sample was around $87 \mathrm{~nm}$. This further confirmed that starch maleate was self-assembled into nanospheres upon precipitation in ethanol.

3.4. Fluorescence Properties of FISM Nanoparticles. FISM nanoparticles showed an excitation and emission peak at $495 \mathrm{~nm}$ and $518 \mathrm{~nm}$ (Figure 5(a)). Effect of $\mathrm{pH}$ on the fluorescence intensity of FISM nanoparticles was shown in Figure 5(b). The FISM nanoparticles were $\mathrm{pH}$ sensitive due to carbonyl and hydroxyl groups of FITC attached onto starch maleate. The fluorescence intensity of FISM increased with increasing $\mathrm{pH}$ up to $\mathrm{pH} 9$, and under this condition FITC was completely ionized and in its most fluorescent form. The observed high fluorescence intensity might be due to a more dianion species of FITC which was presented in a basic solution of FISM sample [9]. However, when $\mathrm{pH}$ was above 9, the fluorescence intensity of the FISM nanoparticles was observed to decrease. We speculated that FITC was unstable at extreme high $\mathrm{pH}$ and hydrolysis of the thiocarbamoyl linkage would occur and result in self-quenching. Therefore, $\mathrm{pH} 9$ was chosen for all further experiments since the highest fluorescence intensity was obtained at this $\mathrm{pH}$.

3.5. Analytical Characteristics. Figure 6 shows the corresponding fluorescence signal changes of FISM upon addition of 0.5 and $1.0 \mathrm{mM}$ of various metal ions to the FISM suspension. The fluorescence intensity of FISM samples was observed to be quenched by most of the heavy metals ions tested in this study. As illustrated in Figure 7, more significant quenching was observed for $\mathrm{Ag}^{+}$and $\mathrm{Pb}^{2+}$ ions as compared to the other metal ions. This finding suggested direct interaction of the metal ions with the thiol group [33]

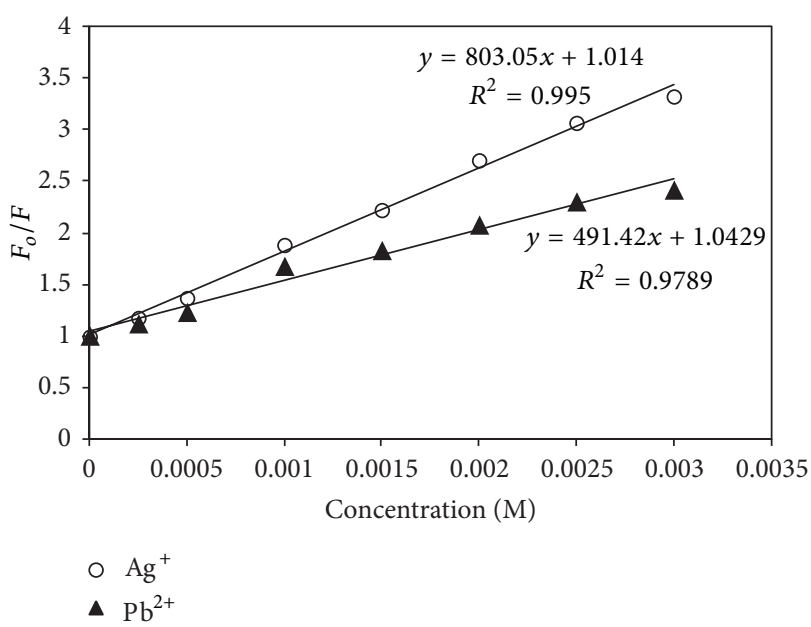

FIGURE 8: Stern-Volmer plots for fluorescence quenching of FISM nanoparticles by $\mathrm{Ag}^{+}$and $\mathrm{Pb}^{2+}$ in buffer solution of $\mathrm{pH} 9$.

of FITC in FISM. Large amounts of $\mathrm{Ag}^{+}$and $\mathrm{Pb}^{2+}$ ions were bound to the FITC molecules which caused the fluorescence intensity of FISM to be significantly quenched.

Figure 7 depicts the fluorescence emission spectra changes upon addition of $\mathrm{Ag}^{+}$and $\mathrm{Pb}^{2+}$ to FISM nanoparticles in buffer solution of $\mathrm{pH} 9$. The fluorescence intensity of FISM sample was quenched upon addition of $\mathrm{Ag}^{+}$and $\mathrm{Pb}^{2+}$ ions up to $5 \mathrm{mM}$, beyond which no more significant signal change was observed. The quenching data can be quantitatively presented in the Stern-Volmer plot (Figure 8), based on $F_{0} / F$ versus $\left[\mathrm{Ag}^{+}\right]$and $\left[\mathrm{Pb}^{2+}\right]$ according to $[31]$

$$
\frac{F_{0}}{F}=1+K_{\mathrm{SV}}[Q]
$$

where $F_{0}$ and $F$ are the fluorescence intensities at $518 \mathrm{~nm}$ in the absence and presence of varying amounts of $\mathrm{Ag}^{+}$and $\mathrm{Pb}^{2+}$, respectively, $K_{\mathrm{SV}}$ and $[\mathrm{Q}]$ are Stern-Volmer quenching 
constant and concentration of the quenchers. Linear SternVolmer plots were observed for both $\mathrm{Ag}^{+}$and $\mathrm{Pb}^{2+}$ with slopes being equal to $K_{\mathrm{SV}}$. Under optimum conditions, $K_{\mathrm{SV}}$ values for $\mathrm{Ag}^{+}$and $\mathrm{Pb}^{2+}$ ions were $8.3 \times 10^{2} \mathrm{M}^{-1}$ and $5.4 \times$ $10^{2} \mathrm{M}^{-1}$ and LOD values were determined to be $2.55 \times 10^{-5} \mathrm{M}$ and $3.64 \times 10^{-5} \mathrm{M}$ for $\mathrm{Ag}^{+}$and $\mathrm{Pb}^{2+}$ ions, respectively. This suggested that FISM could potentially be used for $\mathrm{Ag}^{+}$and $\mathrm{Pb}^{2+}$ ions detection with high sensitivity.

\section{Conclusions}

Novel FISM nanoparticles with a mean particle size of around $87 \mathrm{~nm}$ were successfully prepared via the precipitation method. These FISM nanoparticles exhibited high fluorescence intensity in buffer solution of $\mathrm{pH}$ 9. The results of this study demonstrated that these FISM nanoparticles could be used as cheap, effective fluorescent sensing probes for $\mathrm{Ag}^{+}$ and $\mathrm{Pb}^{2+}$ ions with detection limits as low as $2.55 \times 10^{-5} \mathrm{M}$ and $3.64 \times 10^{-5} \mathrm{M}$, respectively.

\section{Conflict of Interests}

The authors declare that they have no conflict of interests regarding the publication of this paper.

\section{Acknowledgments}

Financial support by the Ministry of Higher Education (MOHE) Fundamental Research Grant Scheme (FRGS), Grant no. 01(17)746/2010(32), and MyBrain (MyMaster) Program for graduate scholarship was gratefully acknowledged.

\section{References}

[1] D. R. Lu, C. M. Xiao, and S. J. Xu, "Starch-based completely biodegradable polymer materials," Express Polymer Letters, vol. 3, no. 6, pp. 366-375, 2009.

[2] O. Carp, D. Visinescu, G. Patrinoiu, A. Tirsoaga, C. Paraschiv, and M. Tudose, "Green synthetic strategies of oxide materials: polysaccharides-assisted synthesis. I. polysaccharides roles in metal oxides synthesis," Revue Roumaine de Chimie, vol. 55, no. 10, pp. 705-709, 2010.

[3] S. K. Nitta and K. Numata, "Biopolymer-based nanoparticles for drug, gene delivery and tissue engineering," International Journal of Molecular Sciences, vol. 14, pp. 1629-1654, 2013.

[4] S. N. A. Mohd Yazid, S. F. Chin, S. C. Pang, and S. M. Ng, "Detection of $\mathrm{Sn}$ (II) ions via quenching of the fluorescence of carbon nanodots," Microchimica Acta, vol. 180, pp. 137-143, 2013.

[5] S. F. Chin, S. N. A. Mohd Yazid, S. C. Pang, and S. M. Ng, "Facile synthesis of fluorescent carbon nanodots from starch nanoparticles," Materials Letters, vol. 85, pp. 50-52, 2012.

[6] C. Gonçalves, E. Torrado, T. Martins, P. Pereira, J. Pedrosa, and M. Gama, "Dextrin nanoparticles: studies on the interaction with murine macrophages and blood clearance," Colloids and Surfaces B, vol. 75, no. 2, pp. 483-489, 2010.

[7] X. Jia, X. Chen, Y. Xu, X. Han, and Z. Xu, “Tracing transport of chitosan nanoparticles and molecules in Caco-2 cells by fluorescent labeling," Carbohydrate Polymers, vol. 78, no. 2, pp. 323-329, 2009.
[8] K. Aslan, M. Wu, J. R. Lakowicz, and C. D. Geddes, "Fluorescent core-shell Ag@SiO 2 nanocomposites for metal-enhanced fluorescence and single nanoparticle sensing platforms," Journal of the American Chemical Society, vol. 129, no. 6, pp. 1524-1525, 2007.

[9] Y. Li, Y. Tan, Z. Ning, S. Sun, Y. Gao, and P. Wang, "Design and fabrication of fluorescein-labeled starch-based nanospheres," Carbohydrate Polymers, vol. 86, no. 1, pp. 291-295, 2011.

[10] H. Wondraczek, A. Kotiaho, P. Fardim, and T. Heinze, "Photoactive polysaccharides," Carbohydrate Polymers, vol. 83, no. 3, pp. 1048-1061, 2011.

[11] S. Hornig, C. Biskup, A. Gräfe et al., "Biocompatible fluorescent nanoparticles for $\mathrm{pH}$-sensoring," Soft Matter, vol. 4, no. 6, pp. 1169-1172, 2008.

[12] J. Liu, Y. Zhang, T. Yang et al., "Synthesis, characterization, and application of composite alginate microspheres with magnetic and fluorescent functionalities," Journal of Applied Polymer Science, vol. 113, no. 6, pp. 4042-4051, 2009.

[13] P. Tallury, S. Kar, S. Bamrungsap, Y.-F. Huang, W. Tan, and S. Santra, "Ultra-small water-dispersible fluorescent chitosan nanoparticles: synthesis, characterization and specific targeting," Chemical Communications, no. 17, pp. 2347-2349, 2009.

[14] J. Zhao and J. Wu, "Preparation and characterization of the fluorescent chitosan nanoparticle probe," Chinese Journal of Analytical Chemistry, vol. 34, no. 11, pp. 1555-1559, 2006.

[15] A. M. de Campos, Y. Diebold, E. L. S. Carvalho, A. Sánchez, and M. J. Alonso, "Chitosan nanoparticles as new ocular drug delivery systems: in vitro stability, in vivo fate, and cellular toxicity," Pharmaceutical Research, vol. 21, no. 5, pp. 803-810, 2004.

[16] K. Park, "Polysaccharides-based near-infrared fluorescence nanoprobes for cancer diagnosis," Quantitative Imaging in Medicine and Surgery, vol. 2, no. 2, pp. 106-113, 2012.

[17] L. Basabe-Desmonts, D. N. Reinhoudt, and M. Crego-Calama, "Design of fluorescent materials for chemical sensing," Chemical Society Reviews, vol. 36, no. 6, pp. 993-1017, 2007.

[18] X. Zhang, Study of novel nanoparticle sensors for food $\mathrm{pH}$ and water activity [Ph.D. thesis], Rutgers University, New Brunswick, NJ, USA, 2009.

[19] H. Katas and C. M. Wen, "Preparation and characterization of highly loaded fluorescent chitosan nanoparticles," International Scholarly Research Network Pharmaceutics, vol. 2011, Article ID 246162, 5 pages, 2011.

[20] A. Schulz, S. Hornig, T. Liebert, E. Birckner, T. Heinze, and G. J. Mohr, "Evaluation of fluorescent polysaccharide nanoparticles for pH-sensing," Organic and Biomolecular Chemistry, vol. 7, no. 9, pp. 1884-1889, 2009.

[21] B. Liu, Y. Bao, H. Wang et al., "An efficient conjugated polymer sensor based on the aggregation-induced fluorescence quenching mechanism for the specific detection of palladium and platinum ions," Journal of Materials Chemistry, vol. 22, no. 8, pp. 3555-3561, 2012.

[22] S. S. Tan, S. J. Kim, and E. T. Kool, "Differentiating between fluorescence-quenching metal ions with polyfluorophore sensors built on a DNA backbone," Journal of the American Chemical Society, vol. 133, no. 8, pp. 2664-2671, 2011.

[23] F.-Y. Wu, S. W. Bae, and J.-I. Hong, "A selective fluorescent sensor for $\mathrm{Pb}$ (II) in water," Tetrahedron Letters, vol. 47, no. 50, pp. 8851-8854, 2006.

[24] S. H. Tay, S. C. Pang, and S. F. Chin, "A facile approach for controlled synthesis of hydrophilic starch-based nanoparticles 
from native sago starch," Starch/Stärke, vol. 64, pp. 984-990, 2012.

[25] S. H. Tay, S. C. Pang, and S. F. Chin, "Facile synthesis of starchmaleate monoesters from native sago starch," Carbohydrate Polymers, vol. 88, no. 4, pp. 1195-1200, 2012.

[26] Z. Stojanovic, K. Jeremic, S. Jovanovic, and M. D. Lechner, "A comparison of some methods for the determination on the degree of substitution of carboxylmethyl starch," Starch/Starke, vol. 57, pp. 79-83, 2005.

[27] S. C. Pang, S. F. Chin, S. H. Tay, and F. M. Tchong, "Starchmaleate-polyvinyl alcohol hydrogels with controllable swelling behaviors," Carbohydrate Polymers, vol. 84, no. 1, pp. 424-429, 2011.

[28] W. Li, L. Wu, D. Chen, C. Liu, and R. Sun, "DMAPcatalyzed phthalylation of cellulose with phthalic anhydride in [bmim]Cl," BioResources, vol. 6, no. 3, pp. 2375-2385, 2011.

[29] T. A. Smith, L. M. Bajada, and D. E. Dunstan, "Fluorescence polarization measurements of the local viscosity of hydroxypropyl guar in solution," Macromolecules, vol. 35, no. 7, pp. 2736-2742, 2002.

[30] B. Liu, S. Fletcher, M. Avadisian, P. T. Gunning, and C. C. Gradinaru, "A photostable, $\mathrm{pH}$-invariant fluorescein derivative for single-molecule microscopy," Journal of Fluorescence, vol. 19, no. 5, pp. 915-920, 2009.

[31] H. Li, J. Zhai, and X. Sun, "Sensitive and selective detection of silver(I) ion in aqueous solution using carbon nanoparticles as a cheap, effective fluorescent sensing platform," Langmuir, vol. 27, no. 8, pp. 4305-4308, 2011.

[32] D. Zhang, K. Vangala, D. Jiang, S. Zou, and T. Pechan, "Drop coating deposition raman spectroscopy of fluorescein isothiocyanate labeled protein," Applied Spectroscopy, vol. 64, no. 10, pp. 1078-1085, 2010.

[33] E. M. Ali, Y. Zheng, H.-H. Yu, and J. Y. Ying, "Ultrasensitive $\mathrm{Pb}^{2+}$ detection by glutathione-capped quantum dots," Analytical Chemistry, vol. 79, no. 24, pp. 9452-9458, 2007. 

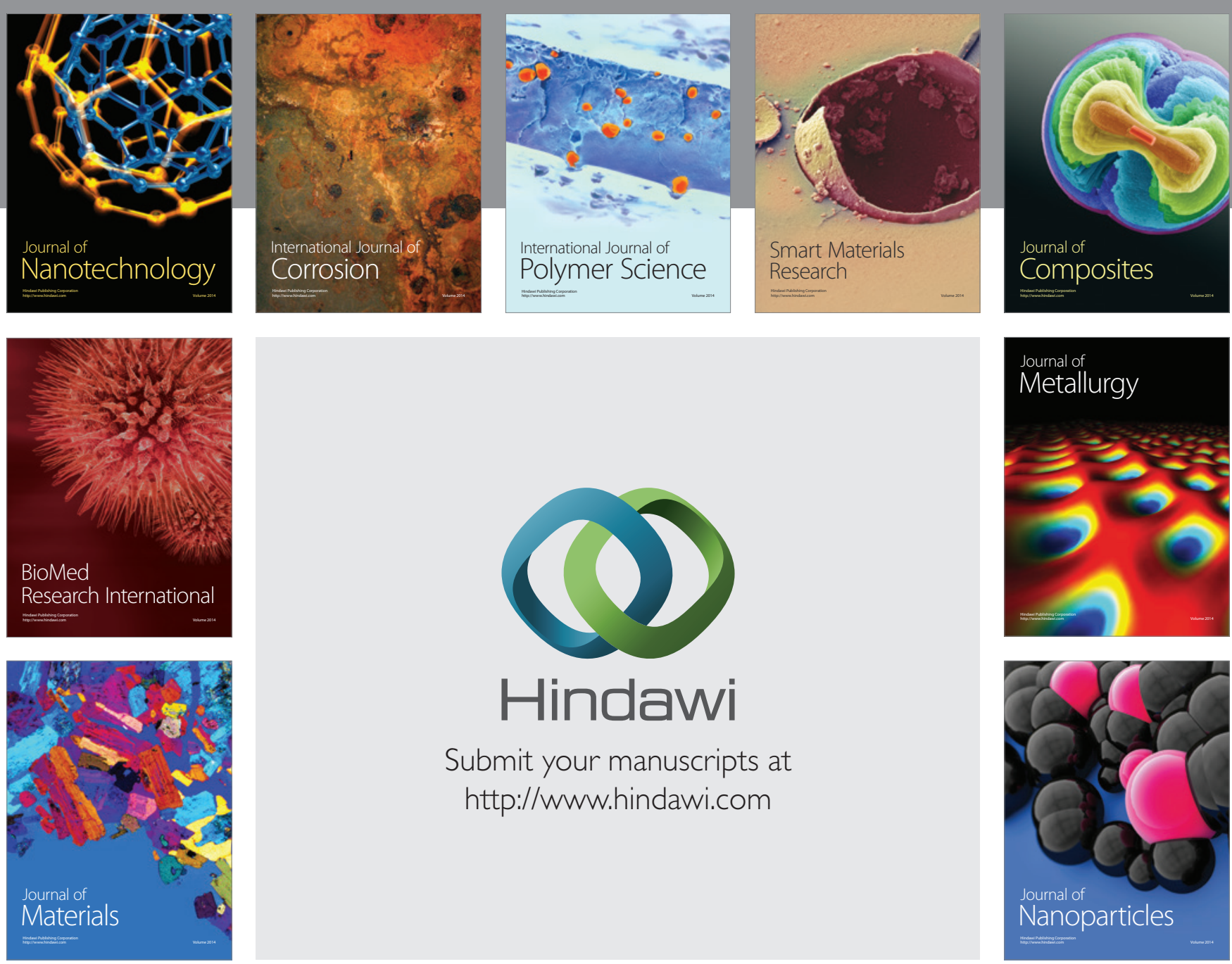

Submit your manuscripts at http://www.hindawi.com
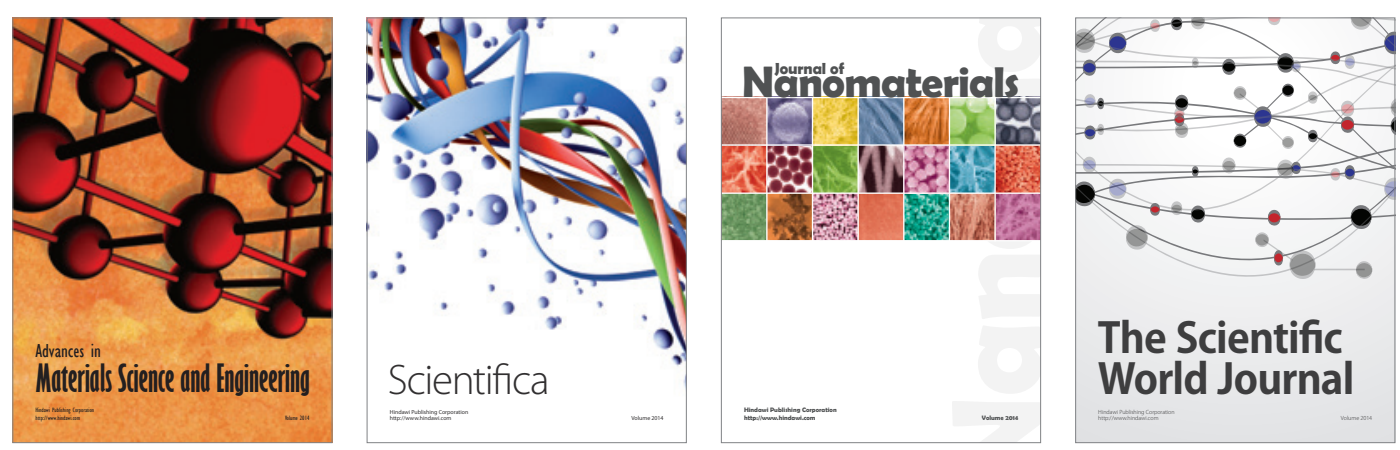

\section{The Scientific World Journal}
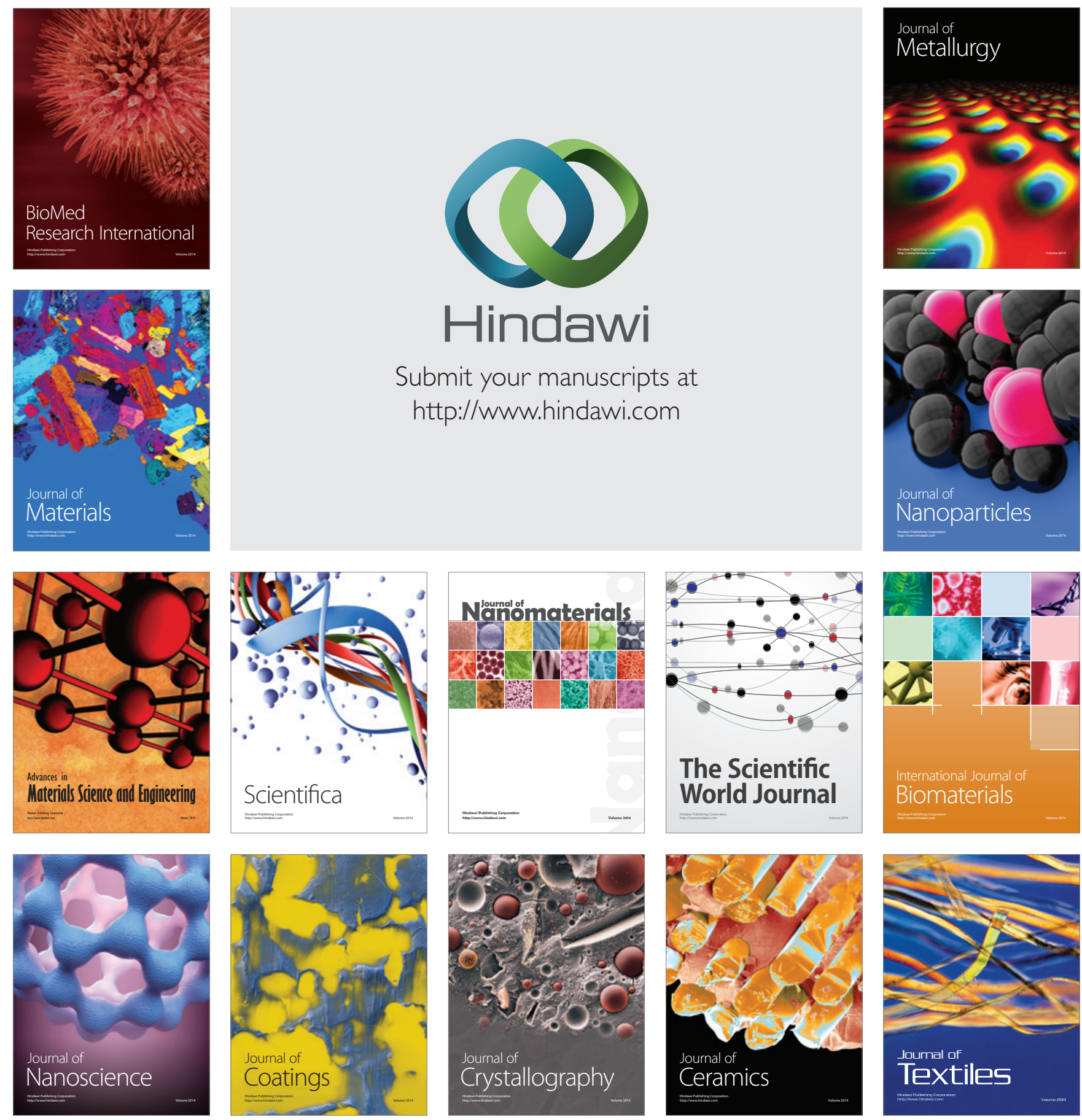